\title{
Occupational Exposure to Dromedaries and Risk for MERS-CoV Infection, Qatar, 2013-2014
}

\author{
Chantal B.E.M. Reusken, ${ }^{1}$ \\ Elmoubasher A.B.A. Farag, ${ }^{1}$ Bart L. Haagmans, ${ }^{1}$ \\ Khaled A. Mohran, ${ }^{1}$ Gert-Jan Godeke, \\ V. Stalin Raj, Farhoud Alhajri, Salih A. Al-Marri, \\ Hamad E. Al-Romaihi, Mohamed Al-Thani, \\ Berend-Jan Bosch, Annemiek A. van der Eijk, \\ Ahmed M. El-Sayed, Adel K. Ibrahim, \\ N. Al-Molawi, Marcel A. Müller, Syed K. Pasha, \\ Christian Drosten, Mohd M. AlHajri, \\ Marion P.G. Koopmans
}

We determined the presence of neutralizing antibodies to Middle East respiratory syndrome coronavirus in persons in Qatar with and without dromedary contact. Antibodies were only detected in those with contact, suggesting dromedary exposure as a risk factor for infection. Findings also showed evidence for substantial underestimation of the infection in populations at risk in Qatar.

$\mathrm{S}$ ince Middle East respiratory syndrome coronavirus (MERS-CoV) was first detected in 2012, approximately 1,000 human infections have been reported to the World Health Organization, all linked to residence in or travel to countries on the Arabian Peninsula (1). Dromedaries (Camelus dromedarius) are thought to play a central role in MERS epidemiology because widespread evidence of MERS-CoV-specific antibodies and virus shedding in camels was found (2), and highly similar viruses have been detected in humans and dromedaries at the same location $(3,4)$. These data suggest a direct zoonotic risk for MERS$\mathrm{CoV}$ infection among persons in contact with camels. We describe a comparative serologic investigation in Qatar

Author affiliations: Erasmus Medical Center, Rotterdam, the Netherlands (C.B.E.M. Reusken, B.L. Haagmans, V.S. Raj, A.A. van der Eijk, M.P.G. Koopmans); Supreme Council of Health, Doha, Qatar (E.A.B.A Farag, S.A. Al-Marri, H.E. Al-Romaihi, M. Al-Thani, A.M. El-Sayed, M.M. AlHajri); Agricultural Research Center, Cairo, Egypt (K.A. Mohran); Ministry of Environment, Doha (K.A. Mohran, F. Alhajri); National Institute for Public Health and the Environment, Bilthoven, the Netherlands (G.-J. Godeke, M.P.G. Koopmans); Utrecht University, Utrecht, the Netherlands (B.-J. Bosch); Leawaina Camel Hospital, Dukhan, Qatar (A.K. Ibrahim, S.K. Pasha); Hamad Medical Centre, Doha (N. Al-Molawi); University of Bonn Medical Center, Bonn, Germany (M.M. Müller, C. Drosten)

DOI: http://dx.doi.org/10.3201/eid2108.150481 among persons with and without daily occupational exposure to dromedaries.

\section{The Study}

We used 498 anonymized serum samples from persons in Qatar with and without dromedary contact (online Technical Appendix, http://wwwnc.cdc.gov/EID/article/21/8/150481-Techapp1.pdf) and control serum from Europe (National Institute for Public Health and the Environment, Bilthoven, the Netherlands; and University of Bonn, Bonn, Germany). Sampling in Qatar was cleared by the Ethics and Institutional Animal Care and Use Committees of the Medical Research Center, Hamad Medical Corporation (permit 2014-01-001). Samples from the Netherlands were used in accordance with the Dutch Federation of Medical Scientific Associations' code of conduct for proper use of human tissue. Samples from Germany were used in accordance with German national laws.

Of the 498 samples, 294 were from persons with daily occupational contact with dromedaries (cohorts A-D) and 204 were from persons without camel contact (cohorts E-G). Cohort A consisted of 109 healthy workers (5 camel slaughterers [subcohort A1] and 104 sheep slaughterers [A2]) at the central slaughterhouse in Doha, Qatar. All workers lived together and had contact with camels and sheep at the central animal market (CAM). Cohort B consisted of 8 CAM workers. Cohort $C$ consisted of 22 healthy men living and working at the Al Shahaniya barn complex near the international dromedary racing track, and cohort D consisted of 155 healthy men living and working on a dromedary farm in Dukhan, western Qatar; molecular data showed ongoing circulation of MERS-CoV in dromedaries in these locations (online Technical Appendix). Cohort E consisted of 56 random samples from construction workers in Qatar. Cohort F consisted of 10 samples from persons working and living at a complex with 200 sheep barns in northern Qatar. Cohort G consisted of 138 samples for confirming specificity of the testing algorithm (66 samples from the Netherlands and Germany from persons with recent human $\mathrm{CoV}$ infection [subcohort G1] and 72 samples from the Netherlands obtained for routine testing from persons with suspected Bordetella pertussis infection [G2]).

We used microarray technology as described $(3,5,6)$ to analyze samples for the presence of $\operatorname{IgG}$ reactive with MERS-CoV S1 antigen (Table). To avoid overinterpretation of data, we set the reactivity cutoff at 30,000 relative

${ }^{1}$ These first authors contributed equally to this article. 
Exposure to Dromedaries and Risk for MERS-CoV

Table. Results of MERS-CoV serologic testing of humans with and without dromedary contact, Qatar, 2013-2014*

\begin{tabular}{|c|c|c|c|c|}
\hline \multirow[b]{3}{*}{ Exposure type, cohort } & \multirow[b]{3}{*}{ Country } & \multicolumn{3}{|c|}{ Serum samples tested by } \\
\hline & & \multirow{2}{*}{$\begin{array}{c}\text { S1 assay, no. } \\
\text { positive/no. tested }\end{array}$} & \multicolumn{2}{|c|}{$\mathrm{PRNT}_{90}$, no. positive/no. tested $\dagger$} \\
\hline & & & S1-positive & S1-negative \\
\hline Dromedary contact & & $20 / 294$ & $10 / 20$ & $1 / 35$ \\
\hline \multicolumn{5}{|l|}{ A, slaughterhouse workers } \\
\hline A1, camel slaughterers & Qatar & $4 / 5$ & $2 / 4(40,20)$ & NT \\
\hline $\begin{array}{l}\text { A2, sheep slaughterers (contact with camels/camel } \\
\text { slaughterers) }\end{array}$ & Qatar & $3 / 104$ & $2 / 3(20,20)$ & $1 / 16(20)$ \\
\hline $\mathrm{B}$, central animal market workers & Qatar & $1 / 8$ & 0 & NT \\
\hline $\mathrm{C}$, barn workers at international camel racing track & Qatar & $4 / 22$ & $3 / 4(40,40,20)$ & NT \\
\hline $\mathrm{D}$, camel farm workers & Qatar & $8 / 155$ & $3 / 8(40,40,20)$ & $0 / 19$ \\
\hline No dromedary contact & & $0 / 204$ & NA & $0 / 48$ \\
\hline $\mathrm{E}$, construction workers & Qatar & $0 / 56$ & NA & $0 / 48$ \\
\hline$\vec{F}$, sheep farmers & Qatar & $0 / 10$ & NA & NT \\
\hline \multicolumn{5}{|l|}{$\mathrm{G}$, specificity controls } \\
\hline $\mathrm{G} 1$, recent infection with a common hCoV & GER, NL & $0 / 66$ & NA & NT \\
\hline G2, suspected infection with Bordetella pertussis & NL & $0 / 72$ & NA & NT \\
\hline
\end{tabular}

fluorescent units for subsequent analyses (6). Samples from 20 of 294 persons with camel contact were reactive; no control or noncontact samples were reactive. Among camel handlers at the Al Shahaniya and Dukhan locations, 4 of 22 and 8 of 155 , respectively, had antibodies to MERS-CoV S1. At the CAM, 1 of 8 handlers had antibodies. At the slaughterhouse location, 3 of 104 sheep slaughterers and 4 of 5 camel slaughterers were antibody-positive (Figure).

Samples from subcohort G1 $(n=66)$ and from all camel-contact cohorts were tested for antibodies to $\mathrm{CoV}$ OC43 S1, a common human $\mathrm{CoV}$; all showed high seropositivity (range 89\%-100\%) (Figure). All 498 samples were tested for reactivity to severe acute respiratory syndrome $\mathrm{CoV} \mathrm{S1}$; none reacted (Figure).

We used a $90 \%$ plaque-reduction neutralization test $\left(\mathrm{PRNT}_{90}\right)$ to confirm the presence of MERS-CoV-specific antibodies in serum samples from camel handlers. For testing, we used the 20 samples that were reactive to MERS$\mathrm{CoV} \mathrm{S} 1$ and a random selection of nonreactive samples from camel-contact $(\mathrm{n}=35)$ and noncontact $(\mathrm{n}=48)$ cohorts. Results were positive for 10 of the 20 MERS-CoV S1 antibody-positive samples (reciprocal titers of 20 or 40) (Table).

All but 1 of the 35 samples from persons with camel contact who had negative S1 ELISA screening results were negative by PRNT $_{90}$; the positive sample had a reciprocal titer of 20 (Table). All 48 samples from the noncontact cohorts were negative by $\mathrm{PRNT}_{90}$. This finding may indicate an underestimation of MERS-CoV seroprevalence by S1 testing. Furthermore, 6 samples from S1-positive and 2 from S1negative persons with camel contact showed a reciprocal titer of 10, but titers of 10 were not observed in the noncontact cohorts. Five of these 8 reactive samples were also positive in a whole-virus MERS-CoV immunofluorescence assay at dilution 1:100; however, we regarded these as negative to avoid overinterpretation of data (data not shown).

\section{Conclusions}

We detected MERS-CoV neutralizing antibodies in healthy persons who had daily occupational contact with dromedaries but not in persons without such contact. Only limited evidence is available regarding the presence of MERS-CoV antibodies in the general human population or in specific population cohorts. However, an overall seroprevalence of $0.15 \%$ was found in a cross-sectional study in Saudi Arabia, and among slaughterhouse workers, neutralizing antibodies were detected in 5 of 140 participants (7). This finding is similar to our finding among slaughterhouse workers: 7 of 109 were MERS-CoV antibody-positive. Four other studies lacked serologic evidence of MERS-CoV infection in humans with occupational exposure to dromedaries ( 8 11). However, only 1 of those studies documented actual MERS-CoV circulation in dromedaries during human contact, and it was concluded that MERS-CoV was not highly transmissible from camels to humans, although only 7 persons had regular contact with only 1 herd (8). On several occasions, the percentage of camels shedding MERS-CoV was high $(60 \%)$ at the CAM and slaughterhouse (C.B.E.M. Reusken, unpub. data). Thus, locations with a continuous flow of dromedaries with different places of origin and different immune statuses may enable prolonged circulation of MERS-CoV and sustained exposure of dromedary handlers to the virus; in Qatar, such locations would include the CAM, slaughterhouse, and barns near the international racing tracks.

In this study, $\mathrm{PRNT}_{90}$-derived antibody titers were relatively low compared with those from earlier studies of MERS patients and dromedaries (2); B.L. Haagmans, unpub. data). The lower titers might reflect the apparent asymptomatic manifestation of MERS-CoV infection, individual differences in susceptibility, or both (2). Also, primary infections may result in a short-lived antibody peak followed by a rapid waning of antibody, depending on virus 




B

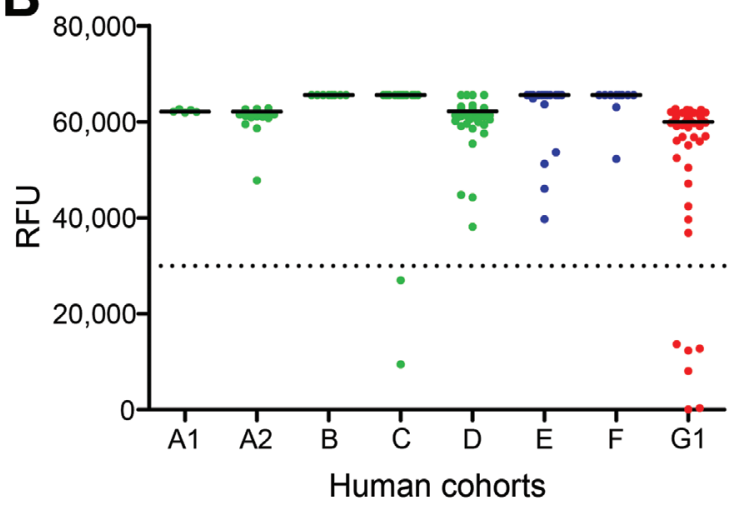

C

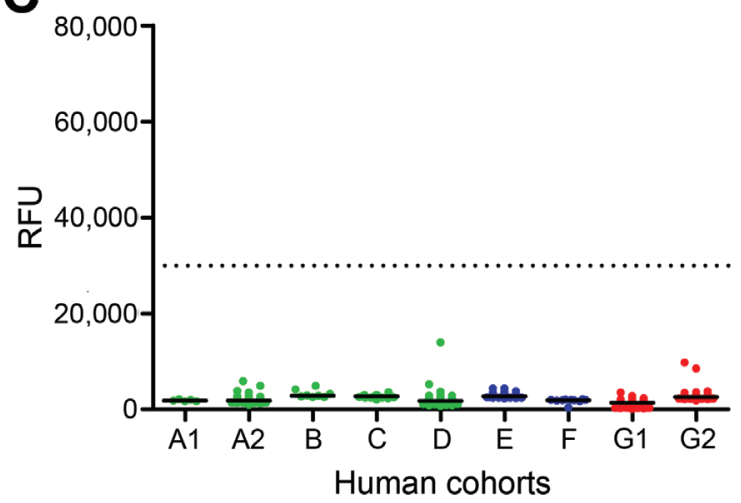

Figure. Reactivity of human serum samples, from persons with and without dromedary contact, with $\mathrm{S} 1$ antigens of various coronaviruses (CoVs), Qatar, 2013-2014. A) Middle East respiratory syndrome CoV S1; B) human CoV OC43 S1; C) severe acute respiratory syndrome CoV S1. Relative fluorescent units (RFU) are shown at a serum dilution of 1:20. Black lines indicate median; dotted black lines at 30,000 RFU depict cutoff for analysis. Human cohorts: A1, camel slaughterers; A2, sheep slaughterers who had contact with dromedaries and camel slaughterers; $\mathrm{B}$, workers at the central animal market; $\mathrm{C}$, barn workers at the international camel racing track; D, workers on camel farms; $E$, construction workers; F, sheep farmers; G1, persons recently infected with a common human CoV (serum samples from the Netherlands and Germany); G2, persons with suspected Bordetella pertussis infection (serum samples from the Netherlands). and host properties (12), as seen in influenza $\mathrm{A}(\mathrm{H} 5 \mathrm{~N} 1)$ virus infection: antibody levels are higher in symptomatic than asymptomatic H5N1-infected persons, and antibodies wane more quickly during asymptomatic infection (13). MERS$\mathrm{CoV}$ antibody kinetics and the persistence of antibodies detected by different serologic methods are not known. Such parameters are needed to estimate the force of infection on the basis of serologic data (14).

MERS-CoV-seropositive participants in this study did not report severe health problems, giving evidence for frequent unrecognized human infections. Assuming the health histories are accurate, this finding implies that the current overall MERS-CoV-associated death rate of $37.1 \%$ (1) is most likely an overestimation of the actual rate and that most infections may be asymptomatic or mild. A major issue to be resolved is whether, and to what extent, asymptomatic cases contribute to the spread of MERS-CoV; it is well recognized that variability in disease transmission exists among humans (15).

\section{Acknowledgments}

We are indebted to Benjamin Meyer for excellent technical assistance. We are grateful to the Joint Supreme Council of Health and Animal Resources Department of Ministry of Environment field investigation team for exceptional research assistance, in particular H. Gobashy and M. El-Maghraby, and to the Doha Camel slaughterhouse veterinarians, staff, and workers for their help. We also thank Ashraf Ayad, Ahmed Salem, Tarik Mosaad Ali al-sharbeeni, Thomas P. Samuel, Redentor Cuizon, Ronald R. Manaor, Khalid Yousif, and Farid Abdoudia for help with collecting samples in the field.

Dr. Reusken is a public health virologist at the Viroscience department of Erasmus Medical Center. Her research interests include viruses operating at the animal-human interface.

\section{References}

1. World Health Organization. Disease outbreak news. Middle East respiratory syndrome coronavirus (MERS-CoV) — Qatar. 2015 Mar 11 [cited 2015 Mar 19]. http://www.who.int/csr/don/ 11-march-2015-mers-qatar/en/

2. Mackay IM, Arden KE. Middle East respiratory syndrome: an emerging coronavirus infection tracked by the crowd. Virus Res. 2015 [cited 2015 Mar 18]. Epub 2015 Feb 2.

3. Haagmans BL, Al Dhahiry SH, Reusken CB, Raj VS, Galiano M, Myers R, et al. Middle East respiratory syndrome coronavirus in dromedary camels: an outbreak investigation. Lancet Infect Dis. 2014;14:140-5. http://dx.doi.org/10.1016/S1473-3099(13)70690-X

4. Memish Z, Cotton M, Meyer B, Watson S, Alsahafi A, Al Rabeeah A, et al. Human infection with MERS coronavirus after exposure to infected camels, Saudi Arabia, 2013. Emerg Infect Dis. 2014;20:1012-5.

5. Reusken CB, Haagmans BL, Muller MA, Gutierrez C, Godeke GJ, Meyer B, et al. Middle East respiratory syndrome coronavirus neutralising serum antibodies in dromedary camels: a comparative serological study. Lancet Infect Dis. 2013;13:859-66. http://dx.doi.org/10.1016/S1473-3099(13)70164-6 
6. Reusken C, Mou H, Godeke GJ, van der Hoek L, Meyer B, Muller MA, et al. Specific serology for emerging human coronaviruses by protein microarray. Euro Surveill. 2013;18:20441.

7. Müller MA, Meyer B, Corman VM, Al-Masri M, Turkestani A, Ritz D, et al. Presence of Middle East respiratory syndrome coronavirus antibodies in Saudi Arabia: a nationwide, crosssectional, serological study. Lancet Infect Dis. 2015;15:559-64. http://dx.doi.org/10.1016/S1473-3099(15)70090-3

8. Hemida MG, Al-Naeem A, Perera RAPM, Chin AWH, Poon LLM, Peiris M. Lack of Middle East respiratory syndrome coronavirus transmission from infected camels. Emerg Infect Dis. 2015;21:699-701. http://dx.doi.org/10.3201/eid2104.141949

9. Memish ZA, Alsahly A, Masri MA, Heil GL, Anderson BD, Peiris M, et al. Sparse evidence of MERS-CoV infection among animal workers living in Southern Saudi Arabia during 2012. Influenza Other Respir Viruses. 2015;9:64-7. http://dx.doi.org/ 10.1111/irv. 12287

10. Aburizaiza AS, Mattes FM, Azhar EI, Hassan AM, Memish ZA, Muth D, et al. Investigation of anti-middle East respiratory syndrome antibodies in blood donors and slaughterhouse workers in Jeddah and Makkah, Saudi Arabia, fall 2012. J Infect Dis. 2014;209:243-6 http://dx.doi.org/10.1093/infdis/jit589.

11. Chu DK, Poon LL, Gomaa MM, Shehata MM, Perera RA, Abu Zeid D. MERS coronaviruses in dromedary camels, Egypt.
Emerg Infect Dis. 2014;20:1049-53. http://dx.doi.org/10.3201/ eid2006.140299

12. Pinschewer DD, Perez M, Jeetendra E, Bachi T, Horvath E, Hengartner $\mathrm{H}$, et al. Kinetics of protective antibodies are determined by the viral surface antigen. J Clin Invest. 2004;114:988-93. http://dx.doi.org/10.1172/JCI200422374

13. Buchy P, Vong S, Chu S, Garcia JM, Hien TT, Hien VM, et al. Kinetics of neutralizing antibodies in patients naturally infected by H5N1 virus. PLoS ONE. 2010;5:e10864. http://dx.doi.org/10.1371/ journal.pone. 0010864

14. Farrington CP. Modelling forces of infection for measles, mumps and rubella. Stat Med. 1990;9:953-67. http://dx.doi.org/10.1002/ sim.4780090811

15. Paull SH, Song S, McClure KM, Sackett LC, Kilpatrick AM, Johnson PT. From superspreaders to disease hotspots: linking transmission across hosts and space. Front Ecol Environ. 2012;10:75-82. http://dx.doi.org/10.1890/110111

Address for correspondence: Chantal B.E.M. Reusken, Erasmus Medical Center, Department of Viroscience, Wytemaweg 8, 3015CN, Rotterdam, the Netherlands; email: c.reusken@erasmusmc.nl; and Mohd M AlHajri, Supreme Council of Health, PO Box 42, Doha, Qatar; email: malhajri1@sch.gov.qa

\section{November 2014: Foodborne Infections}

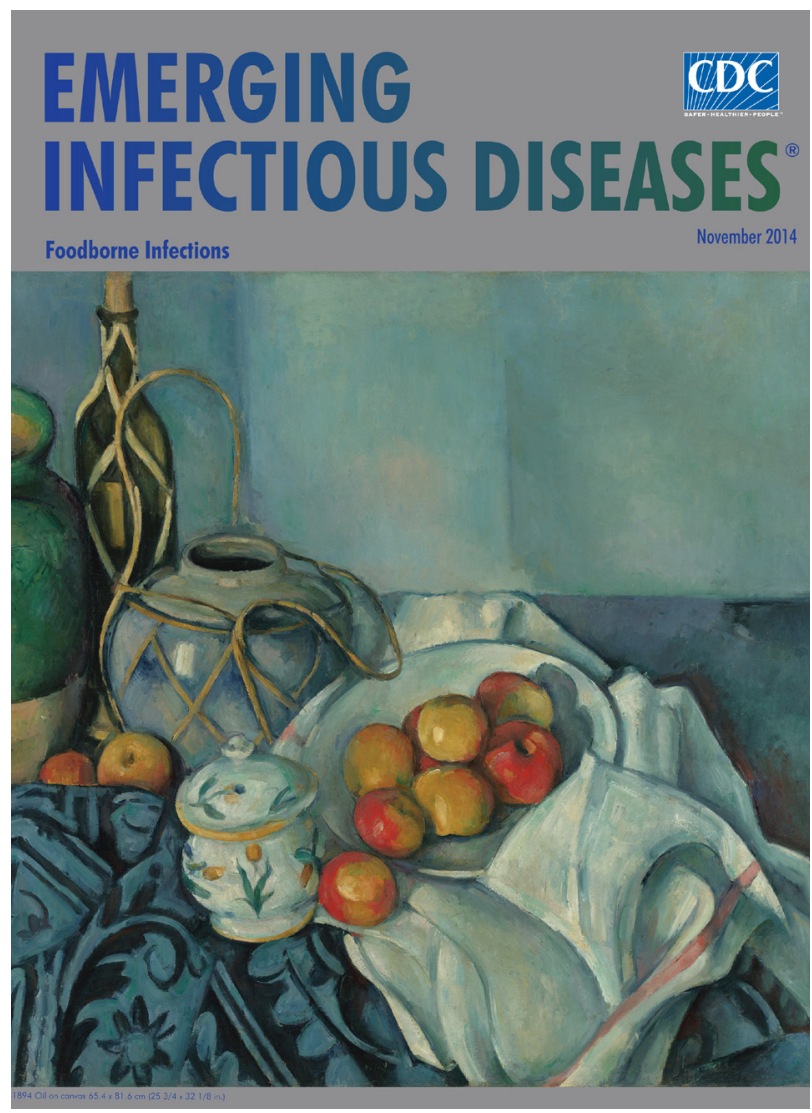

\section{Including:}

- Blastomycosis Mortality Rates, United States, 1990-2010

- Legionnaires' Disease Incidence and Risk Factors, New York, New York, USA, 2002-2011

- Death Patterns during the 1918 Influenza Pandemic in Chile

- Genomic Definition of Hypervirulent and Multidrug-Resistant Klebsiella pneumoniae Clonal Groups

- Respiratory Viruses and Bacteria among Pilgrims during the $2013 \mathrm{Haij}$

- Drug-Resistant Candida glabrata Infection in Cancer Patients

- Novel Chlamydia trachomatis Strains in Heterosexual Sex Partners, Indianapolis, Indiana, USA 